\title{
S1. Organization of psychiatric services
}

\section{THE NORDIC COMPARATIVE STUDY ON SECTORIZED PSYCHIATRY - PATHWAYS TO PSYCHIATRIC CARE RELATED TO PATIFNT CHARACTERISTICS. Terje Oiesvold, Norway, Mikael Sandlund, Sweden. Thomas Zand- ren, Sweden. \\ Salten Psychiatric Centre, 8000 Bodø,Norway; Psychiatric Clinic, Skellefteá, Sweden; Psychiatric Sector of the Central City, Stock- holm, Sweden; Psychiatric Clinic 111, Mora, Sweden; Dep. of Psych- iatry, sector A, Oulu, Finland; Fredriksberg Hospital, Dep. of Psychiatry, Copenhagen, Denmark; Dep. of Psychiatry, Roskilde, Denmark.}

The pathways to psychiatric care are numerous, and one main topic of interest should be whether different patient-groups use different pathways. In the planning of health services one should pay attention to this question. In the nordic comparative study on sectorized psychiatry, seven psychiatric care organizations from four nordic countries have participated. 'New' patients, understood as not having been in contact with the psychiatric care organization for at least 18 months, were collected during one year (2800 patients).

In this study we have looked at the patients whose index-contact was an out-patient contact. These 2159 patients were referred by self $36 \%$; relatives $6 \%$; primary care $27 \%$; general hospitals $11 \%$; social services $2 \%$; other psychiatric services $8 \%$; other sources $8 \%$. In the analyses to be presented two groups are compared: those patients referred by themselves or by their relatives (911 patients) and those referred by primary care ( 578 patients).

In the preliminary analyses some patterns emerge: men and young patients refer themselves to a greater degree; the older ones are to a greater extent referred by primary care as are the widowed, those with sick leave or pension and those with organic and affective psychosis, while the other diagnostic groups are referring themselves more often. There are differences between the care organizations with respect to referral agency. Regarding the patient characteristics, however, the tendencies are much the same from sector to sector. The importance of the primary care especially towards the elderly and some of the psychotics, could be suggested from these findings.
OUTCOME OF COMMUNITY CARE: MULTIDIMENSIONAL ROUTINE EVALUATION OF PSYCHIATRIC PATIENTS IN SOUTH-VERONA AND CAMBERWELL.

*Nicolaou $S$., **Thornicroft $G$., **Taylor $R . \& * R$ uggeri $M$.

* Department of Medical Psychology, Institute of Psychiatry, Universin of Verona. ** PRiSM (Psychiatric Research in Senvice Measurement), Institute of Psychiatry, University of London.

Despite the great number of studies published on community care, very little knowledge exists on the outcome of the integrated interventions which can take place in community-based psychiatric services (CPS). This is mainly attributable to the shortage of naturalistic and longitudinal studies. Therefore, improved planning and evaluation procedures are necessary to assess the efficacy and outcome of community care. The use of standardized instruments and multidimensional measure of outcome is required as part of the routine clinical activities within CPS: these assessments will constitute the basis for naturalistic studies on integrated interventions. The purpose of the present project is to test the feasibility of a standardized routine evaluation of patients treated at CPS, using the following indicators of outcome: psychopathology (Brief Psychiatric Rating Scale), social functioning (Disability Assessment Schedule), needs for care (Camberwell Assessment of Needs), quality of life (Lancashire Quality of Life Profile) and satisfaction with services (Verona Service Satisfaction Scale). The pilot study will start in January 1994. The package of instruments will be administered every six months over a two year period as part of the routine clinical practice. The study will take place, at the same time, in South-Verona and Camberwell. A comparison between the two sites at the first 6 month evaluation will be presented. It is expected that the periodical collection of information will be useful also for routine clinical activities through the use of standardized information for the discussion of clinical cases; moreover, a better definition of the clinical and social profile of the patients in contact with community psychiatric services, in both sites, it is expected. 
L'EVALUATION AU SERVICE DE LA GESTION ET DE LA RECHERCHE? UNE ANNEE DE FONCTIONNEMENT D'UNE UNITE D'ACCUEIL, DE DEPISTAGE ET D'INTERVENTION DE CRISE

A. Brandt A Andreoli

Institutions untversitaires de psychiatrie genevoise, $\mathrm{CH}-1225$, Chêne-Bourg Suisse

L'organisation d'un service de psychiatrie doth être reconsidérée en vue de garantir un meilleur rapport cout-efficacité et de développer la recherche. Pour ce faire, nous avons crée un programme pilote destiné à permettre l'évaluation, ainsi que l'accueil et l'intervention de crise pendant 24 heures de l'ensemble des patients faisant appel à un servlce de secteur couvrant la totalité des soins psychiatriques institutionnels dans une aire de recrutement de 120000 habitants,

à Genève. Les objectifs principaux de ce dispositif étaient: a) subordonner les processus de décision clinique à des guides précis de politique de soins, b) permettre un large recrutement de sujets éligibles pour des programmes de recherche clinique.

Les résuitats sont préliminaires. Les modalités de fonctionnement de l'unité d'évaluation seront discutées ainsl que les instruments utilisés pour les procédés d'évaluation. Les résultats après analyse, indiquent qu'il est possible d'assurer un accueil et une prise en charge de crise chez des patients adressés soit en urgence, soit sur rendez-vous, à un service de psychiatrie communautaire. Il a été, également, possible d'intégrer aux soins des procédures de diagnostic d'évaluation et de décision clinique fiables et un processus de sélection et de recrutement performant pour la recherche.

Nos données confirment l'hypothèse que politiques de psychiatrie communautaire et effort de recherche peuvent être fonctionellement associés et que cette assoclation s'avere bénéfique sur le plan clinique, scientifique et administratif.

A SOCIAL INTEGRATED THERAPEUTIC SYSTEM IN AN EASTERNEUROPEAN TOWN

M. Lazarescu

Psychiatric Clinic, Timisoara, I. Vacarescu 21 str.

R-1900, Timisoara, Romania.

It is presented a therapeutic psychiatric system of the Timisoara city (Romania), as it has been in function for the last 20 years. It's characteristic consist in the tight relationships between it's various parts (psychiatric hospitals, psychiatric departments of the general hospitals, day-hospitals, Mental Health Centres, community services, rehabilitation centres through ambulatory ergotherapy, committee activities, industrial units activities, etc.) A part of the personnel works in a lot of parts of this system, also organizing the continuity of the patients care taking. Are also presented the activities regarding the involvement in the psychiatric therapies and problems of some external collaborators who sympathize with psychiatric problems, the close relationships with the law and the educational local systems, with the self-support associations of the former mental ifl patients and their families, with the national support system for handicapped people, etc. Regarding local hospitals, are presented the programmes for ensuring a healthy community presence into the hospitals, and, for the long course cases, the health unit surveying system that maintain their community fitness. The paper also presents the problems, the good and the bad results of a therapeutic psychiatric system in one of the EasternEuropean cities.
EFFECTS OF COMMUNITY IN A QUASI-EXPERIMENTAL STUDY.

PS Schroder, HH Wernlund, J Aagaard. Aalborg Psychiatric Hospital, Mølleparkvej 10, 9100, Denmark.

The aim of this study is to examine the effects of the establishment of hospital based community psychiatric services in the municipality of Aalborg. The area has been sectorized into three catchment areas, each with similar features regarding background variables. Community psychiatry teams were established lst of September 1990 (a), lst of October 1991 (b) and lst of May 1992 (c), respectively. The time delay in establishment of based community psychiatric services provided a possibility for a quasi-experimental design. Two prevalence studies consisting of all in-and-out-patients attending the services on the 15th of January 1992 (I) and 15th of January 1993 (II) were performed. Data was obtained by standardized schedules from records. During a three month period starting 15 th of January 1992 , all cases were followed up for 12 months. 397 patients attending the services were registered (I) $.51 \%$ of these patients belonged to the primary target group (i.e. patients with chronic of frequent psychotic states and in need of special social intervention). For instance skill therapy at the Aalborg Psychiatric Hospital was consulted by $24 \%$ of these patients. Approx. $50 \%$ of these patients were recruited from the catchment area (c), without a community psychiatric team. The fraction (I) of out-patients in the two areas with a community psychiatric team was respectively 0.48 (a) and 0.39 (b) and only 0.21 (c) in the area without a community psychiatric team. Furthermore the fraction of primary target group patients among the out-patients was 0.57 (a), 0.56 (b) and 0.32 (c). One year later 505 patients (II) attended the psychiatric services. A market growth in the total use of psychiatric services proved to be the case. The study demonstrates that more patients were treated as out-patients in the areas where community psychiatric service was established. Furthermore a larger fraction of the patients in these out-patients groups belonged to the primary target group. Finally, the figures suggest more continuity in treatment, as a result of the establishment of community psychiatry.

\section{EUROPEAN NETWORK FOR MENTAL HEALTH SERVICE EVALUATION} (ENMESH)

Aart H. Schene M.D. Ph.D. (Secretary of ENMESH). Academic Medical Centre, Policlinic Psychiatry (A3.254), Meibergdreet 9, 1105 AZ, Amsterdam, The Netherlands.

The organization of psychiatric services should, if possible, always be combined with evaluation research. In 1991 ENMESH, the European Network for Mental Health Service Evaluation was founded under the co-sponsorship of the World Health Organization, Regional Office for Europe. The aims of ENMESH are:

1. to establish a network of active researchers in mental health service evaluation in Europe

2. to promote the development and dissemination of study designs, research instruments, mental health outcome indicators at individual, service and population levels, and relevant forms of statistical analysis

3. to function as a clearing house for information about mental health service evaluation in Europe. This includes, for example coordinating the gathering, selection and dissemination of ongoing and published evaluation research in mental health care.

At the moment this network has over 170 members from all European countries. In this paper further information about ENMESH will be presented: about its members, their countries of origine, their fields of interest, and ongoing activities.

Secondly the results of the First International ENMESH Conference, which was held June 10-12, 1994 in Amsterdam will be presented. On this conference titled 'Mental Health Service Evaluation; developing reliable measures' four topics were discussed in detail: need assessment, family or caregiver burden, quality of life and satisfaction with services.

Finally the ENMESH agenda for the coming years will be presented. 